\title{
Pregnanolone glutamate, a novel use-dependent NMDA receptor inhibitor, exerts antidepressant-like properties in animal models
}

\author{
Kristina Holubova ${ }^{1}$, Tereza Nekovarova $^{1}$, Jana Pistovcakova ${ }^{2}$, Alexandra Sulcova $^{3}$, Ales Stuchlík ${ }^{1}$ and \\ Karel Vales ${ }^{1 *}$
}

1 Institute of Physiology, Academy of Sciences of the Czech Republic, Prague, Czech Republic

2 Faculty of Medicine, Department of Pharmacology, Masaryk University, Brno, Czech Republic

${ }^{3}$ Central European Institute of Technology, Masaryk University, Brno, Czech Republic

\section{Edited by:}

Tomiki Sumiyoshi, National Center of Neurology and Psychiatry, Japan

Reviewed by:

Christina Dalla, University of Athens,

Greece

Katerina Vladimirovna Savelieva,

Elsevier Inc., USA

*Correspondence:

Karel Vales, Department of

Neurophysiology of Memory, Institute

of Physiology, v.v.i. Academy of

Sciences of the Czech Republic,

Videnska 1083, Prague CZ-14220,

Czech Republic

e-mail:vales@biomed.cas.cz;vales@

fgu.cas.cz
A number of studies demonstrated a rapid onset of an antidepressant effect of noncompetitive $\mathrm{N}$-methyl-D-aspartic acid receptor (NMDAR) antagonists. Nonetheless, its therapeutic potential is rather limited, due to a high coincidence of negative side-effects. Therefore, the challenge seems to be in the development of NMDAR antagonists displaying antidepressant properties, and at the same time maintaining regular physiological function of the NMDAR. Previous results demonstrated that naturally occurring neurosteroid $3 \alpha 5 \beta$-pregnanolone sulfate shows pronounced inhibitory action by a use-dependent mechanism on the tonically active NMDAR. The aim of the present experiments is to find out whether the treatment with pregnanolone $3 \alpha \mathrm{C}$ derivatives affects behavioral response to chronic and acute stress in an animal model of depression. Adult male mice were used throughout the study. Repeated social defeat and forced swimming tests were used as animal models of depression. The effect of the drugs on the locomotor/exploratory activity in the open-field test was also tested together with an effect on anxiety in the elevated plus maze. Results showed that pregnanolone glutamate (PG) did not induce hyperlocomotion, whereas both dizocilpine and ketamine significantly increased spontaneous locomotor activity in the open field. In the elevated plus maze, PG displayed anxiolytic-like properties. In forced swimming, PG prolonged time to the first floating. Acute treatment of PG disinhibited suppressed locomotor activity in the repeatedly defeated group-housed mice. Aggressive behavior of isolated mice was reduced after the chronic 30-day administration of PG. PG showed antidepressant-like and anxiolytic-like properties in the used tests, with minimal side-effects. Since PG combines $\mathrm{GABA}_{A}$ receptor potentiation and use-dependent NMDAR inhibition, synthetic derivatives of neuroactive steroids present a promising strategy for the treatment of mood disorders.

\section{Highlights:}

- 3 $\alpha 5 \beta$-pregnanolone glutamate (PG) is a use-dependent antagonist of NMDA receptors.

- We demonstrated that PG did not induce significant hyperlocomotion.

- We showed that PG displayed anxiolytic-like and antidepressant-like properties.

Keywords: depression, anxiety, NMDA channel blocker, neuroactive steroid, $3 \alpha 5 \beta$-pregnanolone glutamate

\section{INTRODUCTION}

Depressive disorders are among the most common and the most disabling mental diseases. There exist various and widely used antidepressants; however, one of their major limitations is a relatively

Abbreviations: $\mathrm{ACTH}$, adrenocorticotropic hormone; $\beta$-CD, hydroxypropyl- $\beta$ cyclodextrin; CNS, central nervous system; $\mathrm{CRH}$, corticotropin-releasing hormone; DHEA/S, dehydroepiandrosterone sulfate; GABA, $\gamma$-aminobutyric acid; HPA axis, hypothalamic-pituitary-adrenal axis; MK-801, dizocilpine; NMDA, $N$-methyl-Daspartic acid; NMDAR, $N$-methyl-D-aspartic acid receptor; PG, $3 \alpha 5 \beta$-pregnanolone glutamate; SSRI, selective serotonin reuptake inhibitor. long onset of antidepressant effect. But several studies demonstrate antidepressant properties of a single administration of ketamine - the non-competitive $N$-methyl-D-aspartic acid receptor (NMDAR) antagonist (Berman et al., 2000; Zarate et al., 2006, 2012; Diazgranados et al., 2010). Both subjective and objective evaluation of the mood after ketamine administration showed a significant improvement of the mood in the interval spanning from $2 \mathrm{~h}$ to 7 days (Entsuah et al., 2001; Thase et al., 2005). The minimum treatment of $2-4$ weeks (often even more) is required to produce significant improvement in symptomatology with common antidepressants (Lam, 2012), while an infusion of ketamine 
to pharmaco-resistant patients show a similar effect (Murrough et al., 2013). The current hypothesis for the mechanism of ketamine action focuses on a complex cascade of neurochemical events that are induced by ketamine administration. These consequences persist for days after the ketamine elimination. First of all, ketamine administration blocks NMDAR. In all the cases, the protracted antidepressant effect is mediated by the consequent neuroplastic alterations (see Browne and Lucki, 2013; Hayley and Litteljohn, 2014).

It has been more than 20 years since the first proof of antidepressant action of the NMDAR antagonist emerged (Trullas and Skolnick, 1990). Since then, a growing number of evidence confirms that glutamate neurotransmission plays a crucial role in the neuropathology of the depression. Researchers have found that various types of drugs impairing NMDAR functioning (competitive, non-competitive and uncompetitive antagonists, and allosteric modulators) display antidepressant effects in the preclinical (Layer et al., 1995; Rogóz et al., 2002; Li et al., 2011; Burgdorf et al., 2013; Lapidus et al., 2013; Pilc et al., 2013) as well as in the clinical trials (Zarate et al., 2006, 2012). However, the clinical use of NMDA antagonists in pharmacotherapy of mood disorders is hampered by severe side-effects, particularly by psychotic symptoms in humans (Krystal et al., 1994). For this reason, research of the NMDA antagonists is a prominent topic in current neurobiology of the depressive disorder. It focuses on the elucidation of mechanisms of their antidepressant effect, and on the development of novel antidepressants - drugs with antidepressant properties and minimal side-effects, i.e., with more favorable benefit/risk ratio.

Therefore, the research and development of the novel therapeutics based on the NMDA antagonists is necessary in order to avoid psychotomimetic effects. These negative behavioral effects are most pronounced in the case of non-competitive antagonists. Conversely, the behavioral side-effects of the uncompetitive antagonists (antagonists selective for NMDAR containing a NR2B subunit or NMDAR glycine binding site antagonists) are less severe (Danysz et al., 1998; Popik et al., 1998; KarczKubicha et al., 1999; Parsons, 2001; Kemp and McKernan, 2002; Chen and Lipton, 2006).

Neurosteroids are involved in several CNS physiological and pathological processes, such as the response to stress, depression, anxiety, sleep, or memory deficit (see more Morrow, 2007). Antidepressant effects of neuroactive steroids were described in animal models (Urani et al., 2001) as well as in patients (Wolkowitz et al., $1997,1999)$. It has been shown that antidepressant treatment normalized the imbalance of $3 \alpha$ and $3 \beta$ pregnanolone in patients suffering from depression (Romeo et al., 1998; Schüle et al., 2011). During social isolation, an animal model of depression-like behavior, biosynthesis of pregnanolone is significantly decreased (Pinna et al., 2008). SSRI are able to reverse the decreased brain pregnanolone level, and to correct behavioral deficits (Pinna et al., 2006).

The neurosteroids are known for their potentiation as well as inhibition of NMDA and GABA receptors. Naturally occurring $3 \alpha 5 \beta$-pregnanolone sulfate has a substantial inhibitory activity (Irwin et al., 1994; Weaver et al., 2000; Kussius et al., 2009) on tonically activated NMDAR (Petrovic et al.,
2005). Therefore, we introduced the development and testing of a novel synthetic NMDA antagonists derived from the $3 \alpha \mathrm{C}$ pregnanolone having improved pharmacokinetic properties (Rambousek et al., 2011).

The newly synthesized neuroactive steroid $3 \alpha 5 \beta$-pregnanolone glutamate $(P G)$ is a representative member of a group of the steroids exerting effects on $\mathrm{GABA}_{\mathrm{A}}$, AMPA, kainate, and NMDAR. Concerning the NMDAR, the mechanism of an action is not fully understood in detail, but it can be stated that it displays specific properties. The drug is an allosteric inhibitor of the NMDAR. Its degree of inhibition of the NMDAR currents is independent of the cell membrane potential. On the other hand, the binding to its inhibitory binding site is pre-conditioned by the activation of NMDAR by agonists. Therefore, it is so-called a use-dependent allosteric inhibitor of NMDAR (see Korinek et al., 2011) with more potent inhibition of responses mediated by NR1/NR2C-D receptors, compared to those mediated by the NR1/NR2A-B receptors (Petrovic et al., 2005) and $\mathrm{GABA}_{\mathrm{A}}$ agonist (unpublished data). On the contrary to the non-competitive NMDA antagonists, $3 \alpha 5 \beta$ PG is devoid of its adverse side-effects. $3 \alpha 5 \beta-P G$ binds only to the extrasynaptic and tonically activated NMDAR, which results in use-dependent selectivity (Rambousek et al., 2011).

In the present study, we examined potential antidepressant activity of PG. The effect of a single dose administration of PG was assessed by the Porsolt forced swim test, and by the repeated stress of social defeat, both used as common animal models of depression. The locomotor activity and the anxiolytic properties of PG were evaluated together with an open field and elevated plus maze tests. The effect of the chronic administration of PG on the aggressive behavior of singly housed male mice was evaluated by paired agonistic interactions with the non-aggressive group-housed partners.

\section{MATERIALS AND METHODS ANIMALS Open field, elevated plus maze, and forced swimming studies}

Naive adult male ICR mice (VELAZ s.r.o., Prague, Czech Republic), 15 weeks old and weighing 25-35 g, were used for the experiments. The animals were housed in groups of five in the plastic cages in a keeping of Institute of Physiology, Academy of Sciences of the Czech Republic. The mice had ad libitum access to the laboratory chow and water, except during behavioral experiments, and they were kept in a regulated environment $\left(22^{\circ} \mathrm{C}, 50 \%\right.$ humidity) under a 12-h light/dark cycle (lights on at 06:00 a.m.).

\section{Social defeat and agonistic interaction studies}

Naive adult male mice (ICR strain, VELAZ s.r.o., Prague, Czech Republic, 30-37 g) were used in this study. Food and water were available ad libitum. Mice were housed in a keeping of Department of Pharmacology, Faculty of Medicine of Masaryk University, Brno, either individually without any handling in self-cleaning cages with a grid floor $(8 \mathrm{~cm} \times 6 \mathrm{~cm} \times 13 \mathrm{~cm})$, or in groups of $17-20$ in standard plastic cages $(38 \mathrm{~cm} \times 22 \mathrm{~cm} \times 14 \mathrm{~cm})$ with the floors covered with wooden shavings. The animals were housed, and behavioral testing was performed in a different room during the light phase of the constant light-dark cycle, with lights on at 06:00 and off at 18:00 h. The temperature was maintained at $21^{\circ} \mathrm{C}$, 
and relative humidity was $50 \%$. The group-housed mice were not handled, except on the experimental days. Singly housed mice were handled after 3 weeks of isolation, just during oral administration of PG.

Experiments were carried out between 09:00 a.m. and 06:00 p.m. All animal procedures were conducted in accordance with the European Community Council Directives of November 24, 1986 (86-609/EEC), and the Decree of October 20, 1987 (87-848). The study protocol was approved by the Animal Care Committee of the Institute of Physiology of Academy of Sciences of the Czech Republic and Masaryk University Brno, Faculty of Medicine, Czech Republic.

\section{DRUG ADMINISTRATION}

Drugs and chemicals used in the study were purchased from Sigma-Aldrich (Germany). PG was prepared by the esterification of $3 \alpha$-hydroxy- $5 \beta$-pregnan-20-one (Steraloids Inc., USA) with a protected glutamic acid. The synthesis is thoroughly described in Rambousek et al. (2011). PG solutions were prepared by dissolution of $\mathrm{PG}$ in hydroxypropyl- $\beta$-cyclodextrin $(\beta-\mathrm{CD}, 72 \mathrm{mM}$ saline solution, $\mathrm{pH}$ adjusted to 7.4 by $1 \mathrm{M} \mathrm{NaOH}$ ). $\mathrm{MK}-801$ and ketamine were prepared by dissolution in saline. $\beta$-CD was administered as a control for PG, and saline as a control for dizocilpine (MK-801) and ketamine. Dizocilpine was used as a representative of noncompetitive highly selective NMDA antagonists. In addition, ketamine was used as a non-competitive NMDA antagonist possessing antidepressant activity. In the open-field test, PG was applied i.p. at doses of $0.1,1$, and $10 \mathrm{mg} / \mathrm{kg}$, and dizocilpine at the dose of $0.3 \mathrm{mg} / \mathrm{kg}$, and ketamine at the dose of $10 \mathrm{mg} / \mathrm{kg}$. In the elevated plus maze test, PG was injected i.p. at doses of 1 and $10 \mathrm{mg} / \mathrm{kg}$. In the forced swim test, PG was administered i.p. at doses of $0.1,1$, and $10 \mathrm{mg} / \mathrm{kg}$, and in the social defeat test and agonistic interactions orally at the dose of $1 \mathrm{mg} / \mathrm{kg}$ via gastric tube. In these tests, $P G$ was administered $30 \mathrm{~min}$ prior to behavioral testing at a volume of $1 \mathrm{ml} / \mathrm{kg}$, except for the social defeat test and agonistic interactions, where PG was administered $60 \mathrm{~min}$ prior to testing. In agonistic interactions, $P G$ at the dose of $1 \mathrm{mg} / \mathrm{kg} /$ day was administered orally once daily for 30 days at a volume of $1 \mathrm{ml} / \mathrm{kg}$. All animals received the same volume of liquid per $1 \mathrm{~kg}$ of body weight.

\section{BEHAVIORAL PROCEDURES \\ Open-field test}

The animals were placed individually into a circular open-field arena $(82 \mathrm{~cm}$ in diameter), located in a soundproof room. The locomotor activity in the open field was assessed by placing the animal in the arena immediately after i.p. application of PG, MK-801, ketamine, and their vehicles, and monitoring their activity over 50 min using a video tracking system (iTrack, Biosignal Group, USA). We analyzed the locomotor activity, expressed as a total distance traveled (Figure 1). The number of animals per group was as follows: five animals in ketamine, MK-801 and PG $10 \mathrm{mg} / \mathrm{kg}$ group, seven mice in PG $0.1 \mathrm{mg} / \mathrm{kg}$ group, eight mice in saline and PG $1 \mathrm{mg} / \mathrm{kg}$ group, and nine mice in $\beta$-CD group.

\section{Elevated plus maze}

The apparatus consisted of open arms $(30 \mathrm{~cm} \times 6.5 \mathrm{~cm})$, crossed at right angles, with two arms of the same length enclosed by walls of $15.5 \mathrm{~cm}$ high (closed arms). The whole apparatus was

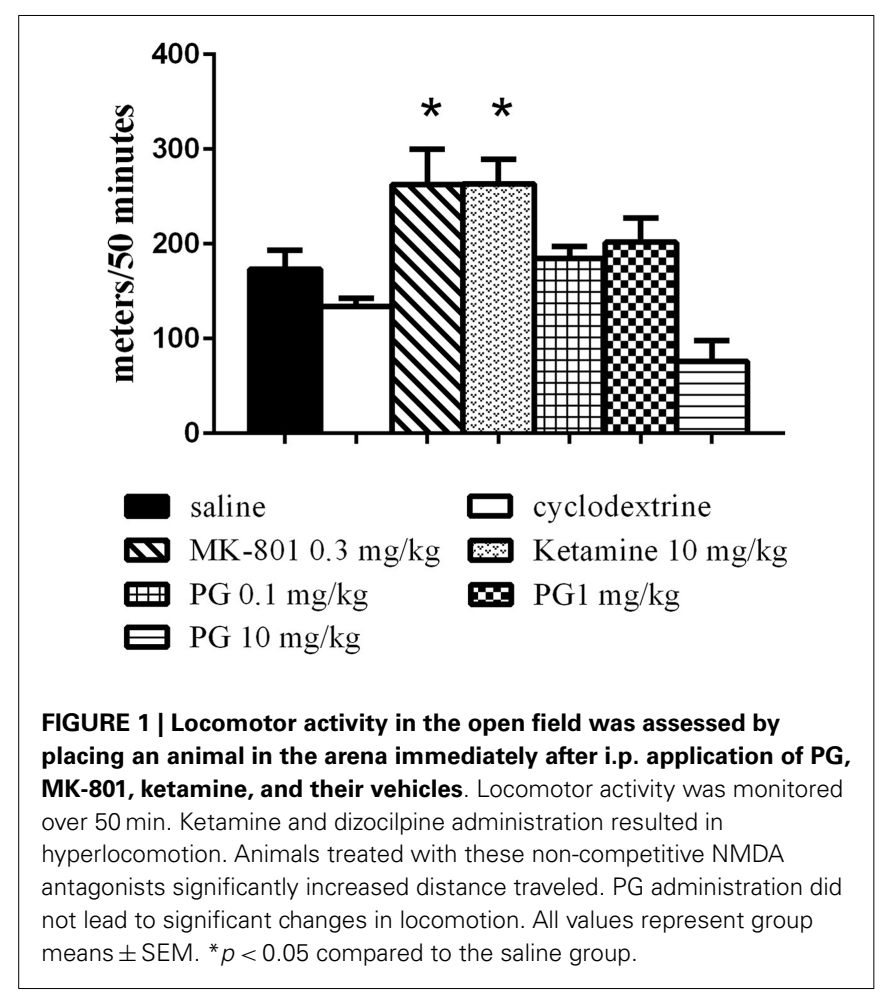

raised $50 \mathrm{~cm}$ above the floor. At the beginning of each session, the mouse was placed on the central platform $(6.5 \mathrm{~cm} \times 6.5 \mathrm{~cm})$ facing the closed arm. The time spent in the open, close arms, and central platform was recorded over a 10-min test session by a video recorder positioned above the maze, tracked, and analyzed by software (iTrack, Biosignal Group, USA). Each experimental group consisted of 10 mice.

\section{Forced swimming}

The forced swimming test was carried out in accordance with the methods described by Porsolt et al. (1978), only with slight modifications. Mice were randomly assigned into the three groups - vehicle treated (10 mice), PG $0.1 \mathrm{mg} / \mathrm{kg}$ treated (10 mice), PG $1 \mathrm{mg} / \mathrm{kg}$ (8 mice), and PG $10 \mathrm{mg} / \mathrm{kg}$ (8 mice) treated mice. Each mouse was placed in a $25-\mathrm{cm}$ plastic transparent cylinder $\left(12 \mathrm{~cm}\right.$ in diameter) containing $10 \mathrm{~cm}$ of water at $24 \pm 1^{\circ} \mathrm{C}$. The mice were left in the cylinder for $6 \mathrm{~min}$, and their behavior was recorded. The duration of immobility was scored in the last $4 \mathrm{~min}$ of the swimming test. Mice were considered to be immobile if they floated while making only necessary movements to keep the head above water (Porsolt et al., 1978). In addition to immobility duration, we analyzed time to the first floating. Latency was measured immediately after the mice were put into the water. Recorded videos were analyzed by two independent observers, blind to the treatment conditions. Analysis was performed by Observer 3.0 (Noldus Information Technology, The Netherlands) software, and the results were displayed as ethograms in excel tables.

\section{Social defeat}

The chronic social defeat stress procedure was carried out using a similar method, described by Sulcova and Krsiak (1987) and Pistovcakova et al. (2005). In the first part of the experiment, mice 
were given $\beta$-CD (14 mice) or PG (18 mice) orally via a gastric tube. Administration was carried out in a randomized order, 60 min prior to the open-field test observations performed in the identical animal cage, but in a different room from that used for the social defeat interactions. Each animal was placed singly into the center of a novel environment (arena $30 \mathrm{~cm} \times 30 \mathrm{~cm}$ ) of the PC-controlled tracking apparatus Acti-track (Panlab, S.L., Spain) with the infrared beam sensors. Over the 8-min testing period, the overall distance traveled (as a marker of locomotor/exploratory behavior) in the open field was measured. Two days later, each mouse was defeated with a singly housed mouse exhibiting an aggressive behavior in a 4-min paired agonistic interaction. The procedure was repeated four times, 7 days apart. Immediately after the last (fourth) agonistic interaction, each mouse was randomly assigned to the vehicle (12 mice), or the treatment group (6 mice). Sixty minutes following the drug administration, the animal was placed into the open-field arena, and the overall distance traveled was measured, as described above. Mice that received a timid partner instead of an aggressive one were excluded from the experiment, since they were not defeated.

\section{Agonistic interactions}

Prior to the experiment, mice were housed individually for 3 weeks. Each individually singly housed mouse was allowed $30 \mathrm{~min}$ adaptation in a Plexiglas neutral observation cage $(20 \mathrm{~cm} \times 20 \mathrm{~cm} \times 30 \mathrm{~cm})$ with clean wood shavings before it was coupled with a group-housed non-aggressive male partner for 4 min interaction. On the first day of the experiment, each animal received vehicle orally via a gastric tube $60 \mathrm{~min}$ prior to the agonistic interaction. Singly housed mice were divided into two groups, according to their behavior during the control interaction (vehicle treatment) with the group-housed partner: (a) an aggressive one (attacking group-housed mouse at least once), and (b) a timid one [exhibiting no attacks, displaying defensive-escape (timid) behavior toward the group-housed mouse]. The number, latency, and duration of attacks, tail rattles, unrests (aggressive activities), defenses, escapes, alert postures (timid activities), social sniffing, climbing, and following the partner (sociable behavior) exhibited by singly housed mice were recorded and evaluated by the hardware/software Observer 3.1, Noldus Technology, Holland. Aggressive singly housed mice were subdivided into the two groups - one receiving vehicle ( 9 mice) and one receiving PG (11 mice). The agonistic interactions with group-housed mice were video-recorded after 14 and 30 days of vehicle/drug administration. The test protocol was adopted from Sulcova and Krsiak (1987).

\section{STATISTICAL ANALYSIS}

Data are presented as the group means \pm standard error of mean (SEM). Statistical analyses were performed by the program GraphPad Prism 6.0 (San Diego, CA, USA). The statistical significance for the social defeat test was detected by the two-way ANOVA, followed by Sidak's post hoc test. The treatment (two factor level) and the stress (two factor levels) served as independent variables. In the agonistic interaction test, the effect of the treatment (two factor level) and the length of administration (three factor levels) of PG/vehicle were assessed by the two-way repeated measures ANOVA (control interaction first day vs. interactions days 14 th and 30th). In the other tests, where the treatment effect was assessed alone, the one-way ANOVA was conducted. Sidak's post hoc test was used when appropriate. The significant level was set at $p<0.05$.

\section{RESULTS}

\section{OPEN FIELD}

Statistical analysis of the locomotor activity in the open field by the one-way ANOVA showed significant differences in total distance traveled $F(6,40)=8.034, p<0.0001$. MK-801 $0.3 \mathrm{mg} / \mathrm{kg}$ and ketamine $10 \mathrm{mg} / \mathrm{kg}$ induced hyperlocomotion (Figure 1) during $50 \mathrm{~min}$ of an exploration. PG plasma levels were highest 15 min after i.p. administration, and brain neurosteroid level peaks occurred 60 min after i.p. application (Rambousek et al., 2011). Therefore, we chose a time interval of $30 \mathrm{~min}$ after i.p. application of PG for the subsequent tests.

\section{ELEVATED PLUS MAZE}

One-way ANOVAs revealed that PG administered at the dose of $1 \mathrm{mg} / \mathrm{kg}$ significantly increased the time spent in the open arms, $F(2,24)=7.654, p=0.0027$ and decreased the time spent in the central platform, $F(2,24)=10.01, p=0.0007$. Mice treated with PG $10 \mathrm{mg} / \mathrm{kg}$ did not display anxiolytic behavior, and their times spent in the open arms and central platform did not differ from the control group treated with only the vehicle. The treatment had no effect at all on the time spent in the closed arms (Figure 2A). Time spent in the central platform may be indicative of risk assessment behavior. Increased time spent in the central platform may be a sign of hesitation before entering either arm. In order to evaluate locomotor activity in the elevated plus maze, an analysis of open to close arms entries was conducted as well. However, no significant difference was revealed (Figure 2B), probably due to a big variance within each treatment group.

\section{FORCED SWIMMING}

Even though PG treatment led to the slight decrease in immobility time (Figure 3A), none of the doses used significantly reduced the immobility in comparison with the controls. As the next parameter, we assessed the time of the first floating (latency, Figure 3B). One-way ANOVA detected significant elongation of the latency after PG $1 \mathrm{mg} / \mathrm{kg}$ treatment $F(3,29)=5.248, p=0.0051$. The discrepancy between results obtained from immobility and the latency analyses remains to be clarified. Sensitivity of the two parameters to antidepressant treatment may differ.

\section{SOCIAL DEFEAT}

Group-housed mice repeatedly defeated on aggressive agonistic interactions with singly housed partners exhibited decreased locomotor activity in the open field. Two-way ANOVA revealed significant effect of treatment vs. stress interaction $F(1,46)=4.687$, $p=0.0356$. No significance was found for the effect of factor stress and factor treatment. PG $1 \mathrm{mg} / \mathrm{kg}$ administration normalized the stress-induced inhibition of locomotor activity in the open field, expressed as an overall distance traveled (Figure 4). 

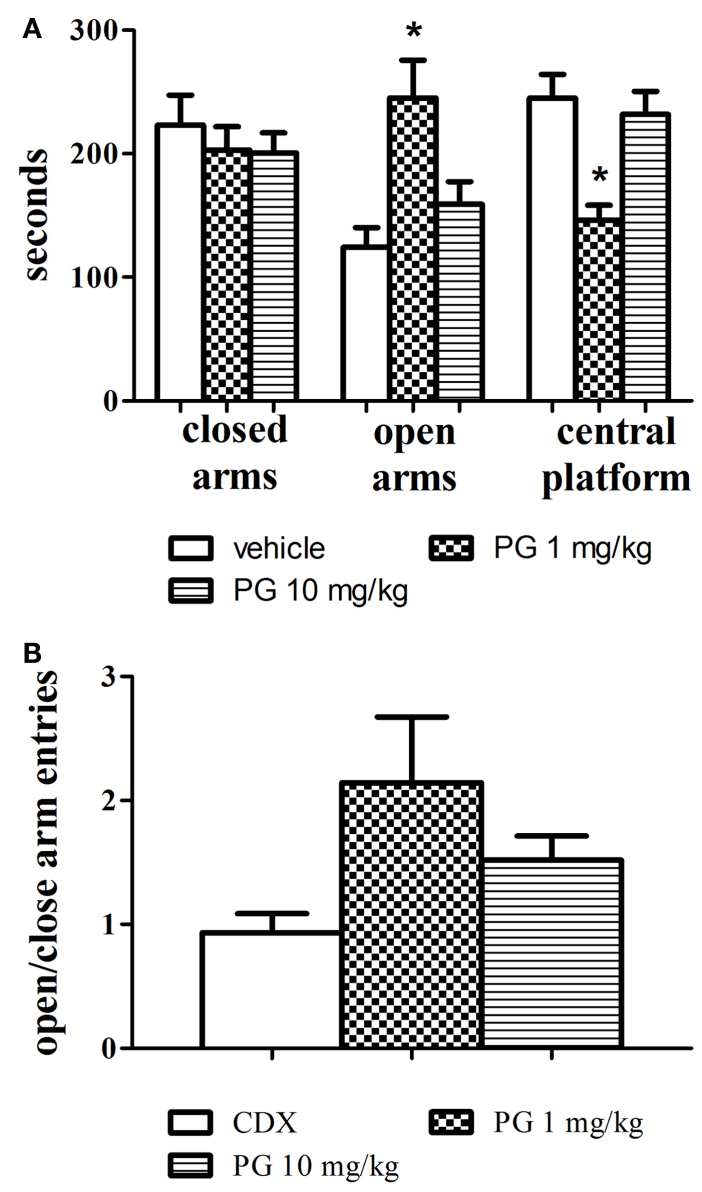

FIGURE 2 | Anxiolytic effect of PG was assessed in an elevated plus maze. (A) PG administered at the dose of $1 \mathrm{mg} / \mathrm{kg}$ significantly increased the time spent in the open arms, and decreased the time spent in the central platform. Mice treated with PG at the dose of $10 \mathrm{mg} / \mathrm{kg}$ did not display anxiolytic behavior. All values represent group means \pm SEM. ${ }^{*} p<0.005$ compared to the vehicle, $\beta$-CD group. (B) The analysis of open to close arm entries did not reveal differences between treatment groups, probably due to big differences in variance within each group. All values represent group means \pm SEM.

\section{AGONISTIC INTERACTIONS}

Chronic administration of PG at the dose of $1 \mathrm{mg} / \mathrm{kg}$ over 30 days reduced aggressive actions in singly housed mice exhibiting aggressive behavior on the first interaction. Two-way repeated measures ANOVA detected significant effect of the treatment vs. the length of administration interaction in the parameter duration $F(2$, $116)=5.407, p=0.0057$. Length of the administration showed significant effect $F(2,116)=11.97, p<0.0001$, whereas treatment showed no influence on the duration of aggression. Aggression was significantly reduced after 14 and 30 days of PG $1 \mathrm{mg} / \mathrm{kg}$ administration, compared to the scores of vehicle treated controls in the first day (Figure 5A). This reduction was more pronounced after 30 days of PG treatment ( $p<0.0001$ post hoc analysis), compared to only 2 weeks treatment $(p=0.0037)$. The time spent in aggressive interactions dropped in PG treated animals.
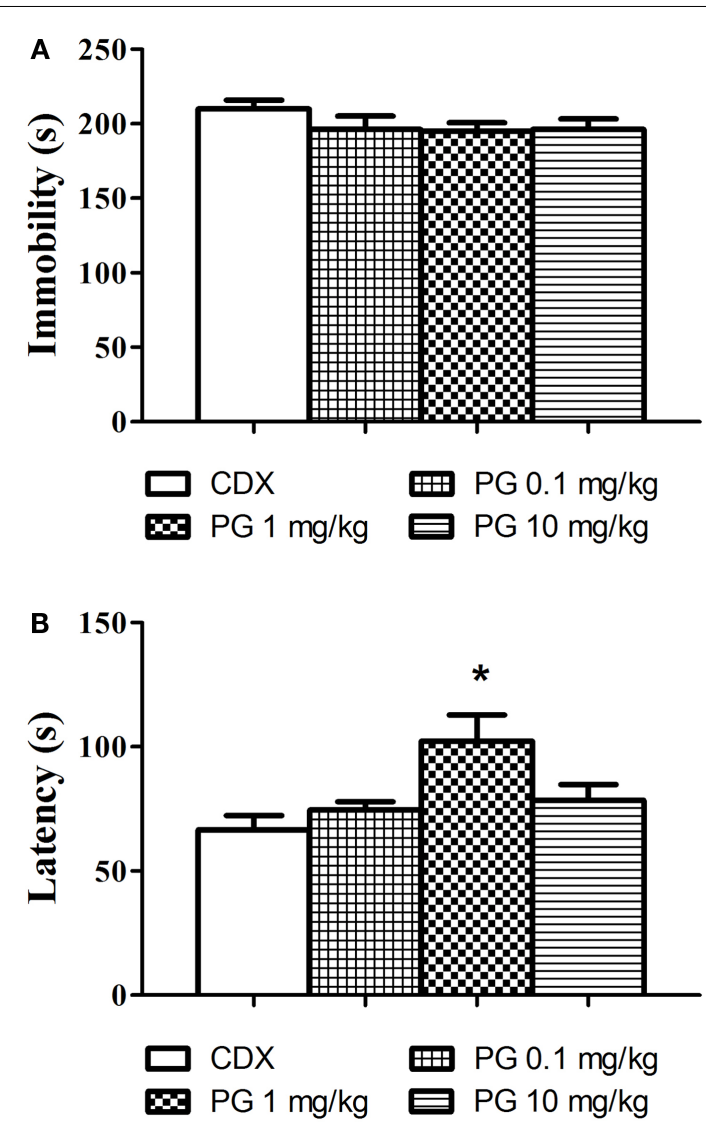

FIGURE 3 | In the forced swim test, we evaluated the possible antidepressant effect of PG. (A) Immobility time in the forced swim test was assessed $30 \mathrm{~min}$ after i.p. administration of PG and vehicle. None of the doses applied significantly influenced floating. Average group values \pm SEM. (B) In addition to immobility duration in the forced swimming test, we measured time to the first floating as well. Administration of PG at the dose of $1 \mathrm{mg} / \mathrm{kg}$ significantly prolonged the latency to the first floating compared to controls. All values represent group means \pm SEM. ${ }^{*} p<0.005$ compared to the vehicle group.

Time to the first aggressive action (the latency) was prolonged in PG treated mice. Two-way repeated measures ANOVA revealed the effect of the factor treatment $F(1,58)=4.55, p=0.0372$ and the factor of administration length $F(2,116)=8.652, p=0.0003$ on the latency. Interaction between the two factors was not significant. It took more time for the PG treated animals to attack the intruder after 14 and 30 days of PG application in comparison to the controls (Figure 5B). Again, this effect was greater after longer administration $(p<0.0001$ after 30 days vs. $p=0.0275$ after 14 days, revealed by post hoc test).

The frequency of aggressive actions decreased over the course of an experiment. Interaction between the two factors, treatment, and length of administration, came out significant $[F(2,116)=8.505$, $p=0.0004]$ when analyzed by the two-way repeated measures ANOVA. The length of administration had a significant effect $F(2$, $116)=30.04, p<0.0001$ on the frequency. The kind of treatment we used had no effect. Frequency expressed as a number of aggressive actions decreased after 14 and 30 days of PG treatment. Vehicle 


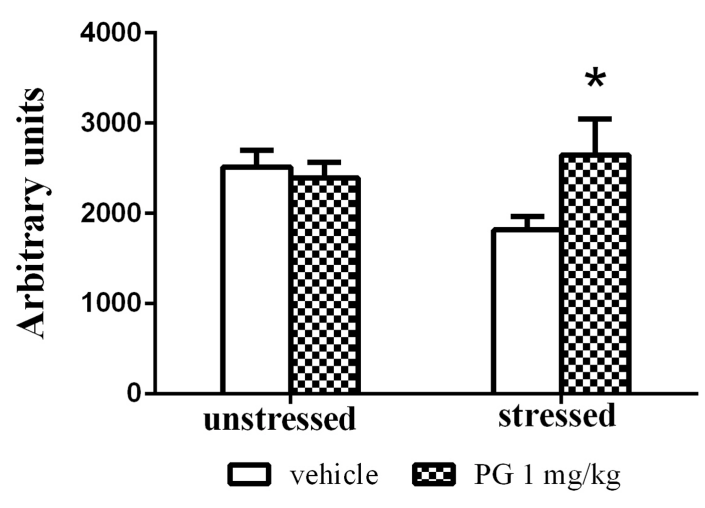

FIGURE 4 | Group-housed mice repeatedly stressed by defeat on four agonistic interactions (7 days apart) with aggressive singly housed partners exhibited depressed locomotor activity in the open field. This effect was disinhibited by treatment with $P G$ at the dose of $1 \mathrm{mg} / \mathrm{kg}$. There was no difference in unstressed animals between two treatment groups in the open-field activity. All values represent group means \pm SEM. ${ }^{*} p<0.05$ compared to the stressed vehicle treated animals.

treated mice also showed significant reduction in the frequency of aggressive actions between the 1st and 30th day. However, this change in frequency was not as prominent $(p=0.0163)$ as in PG treated animals ( $p<0.0001$ for both time intervals) (Figure 5C). Taken altogether, mice treated daily with PG at the dose of $1 \mathrm{mg} / \mathrm{kg}$ over the course of 30 days indulged less in aggressive interactions.

\section{DISCUSSION}

The present study focused on the evaluation of antidepressant-like and anxiolytic-like effects of newly synthesized neurosteroid PG. Neurosteroids are known for their neuroprotective and antipsychotic effects (Pringle et al., 2003; Veiga et al., 2003; MacKenzie et al., 2007; Rambousek et al., 2011; Vales et al., 2012), and alternation of their brain levels is well-documented in various neurodegenerative diseases and aging (Vallée et al., 1997; Nafziger et al., 1998; Kim et al., 2003; Aldred and Mecocci, 2010; Luchetti et al., 2010; Sorwell and Urbanski, 2010). Similarly, the downregulation of neurosteroid synthesis possibly contributes to the development of depressive disorders and anxiety (Morrow, 2007; Schüle et al., 2011, 2014). Neurosteroids as potent NMDAR antagonist and GABA receptor agonists might be promising therapeutic agents in depressive disorders (Zorumski et al., 2013).

Our results from the open-field test indicate that hyperlocomotion found in MK-801 and ketamine treated animals is not present after PG application (Figure 1). It is in concordance with our previous results (Vales et al., 2012). As opposed to noncompetitive NMDA antagonists such as dizocilpine (MK-801), ketamine, and PCP often used for induction of schizophrenia-like behavior (Bubeníková-Valesová et al., 2008), PG does not display psychotomimetic properties, but quite the contrary. Administration of PG at the doses of 0.1 and $1 \mathrm{mg} / \mathrm{kg}$ did not significantly influence spontaneous locomotor activity in comparison to the control (Figure 1). Furthermore, PG at the highest dose of $10 \mathrm{mg} / \mathrm{kg}$ exhibited hypolocomotion after i.p. administration.
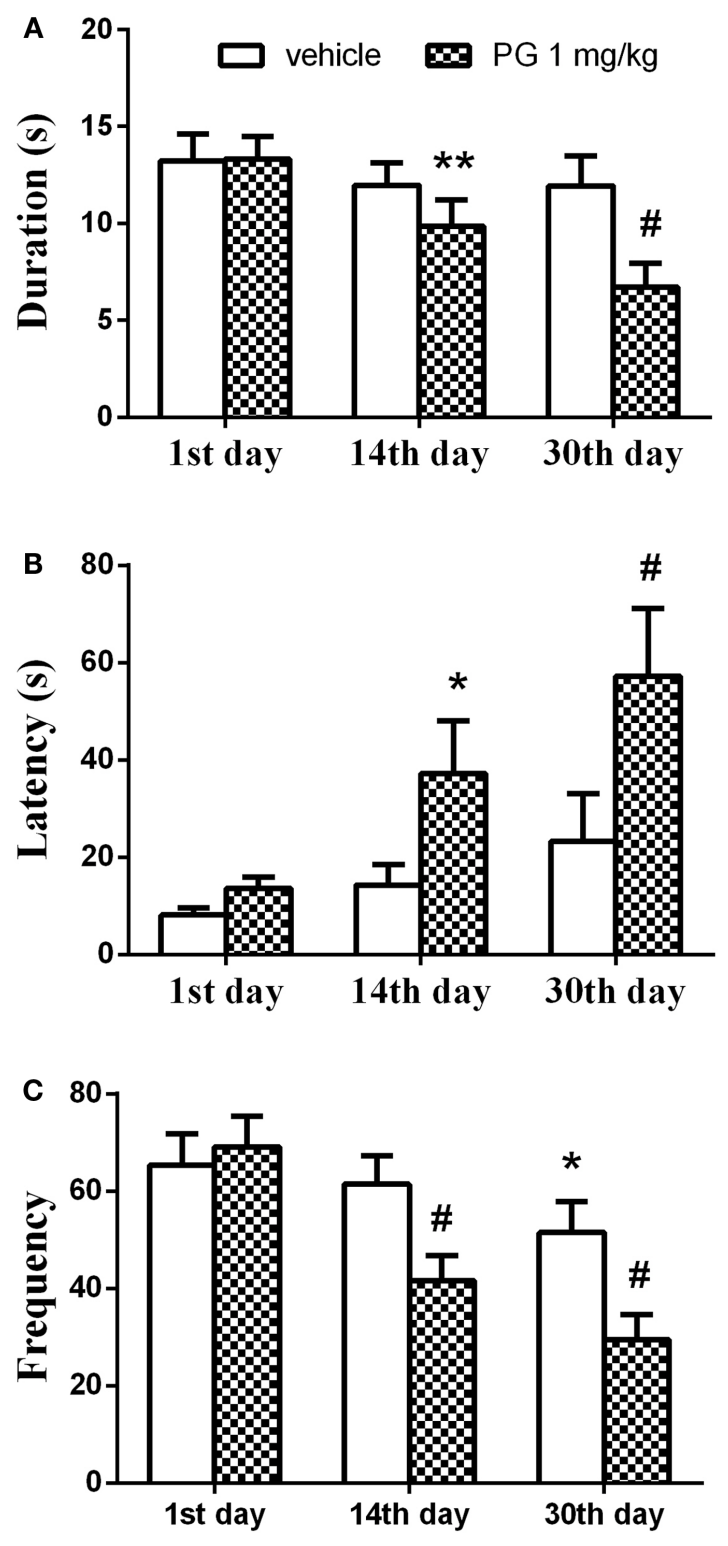

FIGURE 5 | In 4-min paired agonistic interactions, singly housed mice were confronted with non-aggressive group-housed partners. Chronic administration of PG at the dose of $1 \mathrm{mg} / \mathrm{kg}$ over 30 days reduced aggressive behavior in singly housed mice exhibiting aggressive behavior during the first agonistic interaction. (A) Graph shows the duration of aggressive activities. The duration was significantly reduced after 14 and 30 days of $P G 1 \mathrm{mg} / \mathrm{kg}$ administration, compared to the scores of vehicle treated controls in the first day. The effect was more prominent after 30 days. (B) Graph shows latency to the first aggressive action. Latency prolonged in PG treated mice after 14 and 30 days of PG application in comparison to controls. Again this effect was greater after longer administration. (C) Graph displays number of aggressive actions. Frequency decreased over the course of the experiment. Vehicle treated mice also showed significant reduction in the frequency of aggressive actions between the 1st and 30th day. However, this change in frequency was not as prominent as in $\mathrm{PG}$ treated animals. All values represent group means \pm SEM. ${ }^{*} p<0.05,{ }^{*} p<0.005,{ }^{*} p<0.0001$ compared to the vehicle treated animals on the first day of agonistic interaction. 
It cannot be interpreted as an unexpected effect, because GABA agonists as well as NMDA antagonists are drugs, which produce typically sedative and anesthetic effects.

The lower risk of hyperlocomotion can be explained by the different mechanism of action. PG is a use-dependent NMDA inhibitor, which has a more pronounced inhibitory action on the tonically active NMDAR (Petrovic et al., 2005). The hypothesis underlying the ability of use-dependent inhibitors to differentiate between phasic physiological and tonic pathological activation of NMDAR during pathological states have gained relatively wide acceptance. However, it is still unclear how such compounds could differentiate between normal and abnormal synaptic activation of NMDAR (Borovska et al., 2012). The lowered risk of hyperlocomotion displays memantine as well. Memantine has been shown to result in the preferential blockade of excessive NMDAR activity, while sparing normal excitatory synaptic function (Lipton, 2006, 2007).

Anxiolytic performance of PG was assessed in the elevated plus maze test. Agonists of GABA receptors are recognized for their anxiolytic properties (Brot et al., 1997), and in the elevated plus maze test they increase the time spent in open arms (Rodgers and Johnson, 1998). PG at the dose of $1 \mathrm{mg} / \mathrm{kg}$ exhibited anxiolyticlike activity clearly indicated by significant increase in time spent in open arms (Figure 2A). Anxiolytic-like properties of PG were also previously confirmed by decreased shock-induced ultrasonic vocalization in rats after PG application (Vales et al., 2012). The analysis of open to close arm entries did not reveal differences between treatment groups (Figure 2B), however the decrease in locomotion in the PG of $10 \mathrm{mg} / \mathrm{kg}$ treated group was not as prominent as in the open field. It can be explained by the decreased habituation to the maze, since animals spent considerably less time in the elevated plus maze than in the open field, and the activity of the mice is enforced by the nature of the task.

Pregnenolone glutamate at all doses slightly reduced floating when applied $30 \mathrm{~min}$ prior to the test, however this decrease was not significant (Figure 3A). We analyzed not only the overall time of floating in the session, but also the time to the first floating. In our experiment, PG $1 \mathrm{mg} / \mathrm{kg}$ significantly prolonged the latency to the first immobility (Figure 3B). Time to the first floating analysis produced more robust results, at least in our experimental set-up. According to literature available and our experience, the forced swim test is sensitive to various independent variables, such as mouse strains (Lucki et al., 2001; Mason et al., 2009), age of mice used (Mason et al., 2009; Sequeira-Cordero et al., 2013), water temperature (Pintér et al., 2011), 2 days vs. 1 day protocol, water depth (Pintér et al., 2011), diameter of cylinders animals swim in, seasonal changes, etc. (Petit-Demouliere et al., 2005). We probably failed to find the optimal protocol where the differences between the groups would be more distinct.

$3 \alpha$-reduced neuroactive steroids have anxiolytic and antidepressant-like effects in the preclinical studies (Eser et al., 2006). Even though PG meets this effect, it failed to improve immobility scores in the forced swim test. Similar results were obtained after progesterone application (Urani et al., 2001). However, the administration of allopregnanolone significantly reduced the time spent by immobilization (Rodríguez-Landa et al., 2009), indicating that allopregnanolone is a more potent GABA activator, compared to progesterone. The mechanism of action of PG on GABA neurons is not fully known. If the failure to decrease immobility in the forced swimming could be ascribed to the lower affinity of PG to GABA receptors, or if it is caused by the methodological drawbacks in the test, remains to be clarified.

Pregnenolone glutamate at the particular dose of $1 \mathrm{mg} / \mathrm{kg}$ had the most pronounced effect in the tests mentioned above. Therefore, we decided to use this concentration in the repeated social defeat model. This animal model of depressive disorder is more plausible than the forced swim test, since it mimics a different aspect of depression by prolonged exposure to psychosocial stress (Chaouloff, 2013; Venzala et al., 2013). In the social defeat test, PG at $1 \mathrm{mg} / \mathrm{kg}$ normalized the locomotor activity in the open field in mice exposed to aggressive conspecific prior to open-field testing (Figure 4). Stressed mice receiving no PG exhibited stress-induced reduction in locomotion measured by distance passed. There was no difference in unstressed animals between the two treatment groups in the open-field activity. The spontaneous locomotor activity was not affected by PG administration; this conclusion is also supported by the results from the open field.

The social defeat stress leads to depression-like abnormalities in defeated animals, lasting for weeks, such as anxiety, social avoidance, anhedonia, and changes in body weight, increased blood pressure, suppressed immune responses, and others (Blanchard et al., 2001; Huhman, 2006; Chaouloff, 2013). Among the most often noted behavioral responses is the decrease in activity and exploration in the open field (Meerlo et al., 1996; Rygula et al., 2005; Razzoli et al., 2009). Chronic, but not acute, treatment with antidepressants, both SSRI and tricyclics, can reverse the consequences of social stress exposure (van Bokhoven et al., 2011; Olivares et al., 2012; Venzala et al., 2012). Similarly, NMDAR antagonist (Jasnow et al., 2004) and GABA receptor agonist (Jasnow and Huhman, 2001) microinjected to the amygdala block conditioned defeat.

Aggressive mice after 30 days of single-housing were receiving PG of $1 \mathrm{mg} / \mathrm{kg}$ chronically over 30 days. PG administration led to the significant decrease of aggressive behavior in the agonistic interactions with non-aggressive group-housed partners, when compared to the control interaction in the first day of the experiment. The duration and frequency of the aggressive behavior decreased after 14 days of chronic application of PG. An even more profound effect was reached after 30 days of application (Figures 5A,C). The significant decrease in frequency was also detected in vehicle treated animals 30 days after $\beta$-CD administration. However, this effect was less prominent, compared to PG treated animals (Figure 5C), and it might be caused by habituation to intruder. The latency to the first aggressive action was prolonged 14 days after PG administration, and it was again accompanied by a more profound effect 30 days after (Figure 5B). Taken together, the mice treated daily with PG at the dose level of $1 \mathrm{mg} / \mathrm{kg}$ over the course of 30 days indulged less in aggressive interactions.

Stress induced by social isolation causes a significant decrease in pregnenolone, progesterone, allotetrahydrodeoxycorticosterone, and allopregnanolone concentrations in the cerebral cortex, compared to the group-housed controls (Serra et al., 2000). The neuroactive steroid changes were not evident after $48 \mathrm{~h}$ of chronic stress exposure, but their decrease was present 7 days after the 
chronic stress, with the most prominent change 30 days after (Serra et al., 2000). Stress and depression are associated with a decrease in GABAergic function in the PFC and hippocampus (Benes et al., 2008; Croarkin et al., 2011). Administration of PG could lead to normalization of the level of GABA potentiating neurosteroids, and therefore contribute to the homeostasis restoration (aggression reduction/normal locomotor activity) by enhancement of the GABA neurotransmission.

Chronic stress reduces the production of allopregnanolone, as well as other GABAergic neurosteroids (Serra et al., 2000). Decreased levels of neurosteroids in the plasma and CSF are found in patients with major depression (Romeo et al., 1998; Uzunova et al., 1998). Prolonged exposure to stress may induce a reduction in pituitary responsiveness to high concentrations of $\mathrm{CRH}$, leading to desensitization, and consequently to decreased ACTH secretion (Hoffman et al., 1985), affecting neurosteroid synthesis. A reduced ACTH response to chronic stress leads to hyper-responsiveness of the hypothalamic-pituitary-adrenal axis (HPA) axis to the new stimuli, and confers vulnerability to mood and anxiety-related disorders, as well as depression (Biggio and Purdy, 2001). Antidepressant treatment normalizes the altered allopregnanolone levels (Uzunov et al., 1996; Uzunova et al., 1998; Schüle et al., 2014) suggesting that GABAergic neurotransmission alteration by the neurosteroids has a therapeutic effect.

The increasing number of evidence shows that the NMDARs play a crucial role in the neurobiology and treatment of depression. PG as the use-dependent inhibitor of NMDARs binds only to the extrasynaptic and tonically activated NMDARs, leaving normal neurotransmission unaffected (Rambousek et al., 2011), and therefore causing less severe side-effects. The effect of neuroactive steroids appears to be subtype selective (Gibbs et al., 2006). Similarly, PG displays more potent inhibition of responses mediated by NR1/NR2C-D receptors, compared to those mediated by NR1/NR2A-B receptors (Petrovic et al., 2005). The current challenge in development of steroidal NMDA antagonists suitable for clinical use is in the low potency of existing drugs. Nonetheless, if both the $\mathrm{GABA}_{\mathrm{A}}$ enhancers and NMDA antagonists have antidepressant potential, the ideal agent might be the one that combines all these effects in a single molecule (Zorumski et al., 2013). Therefore, it might be surprising that DHEA and DHEAS as positive NMDA and negative $\mathrm{GABA}_{\mathrm{A}}$ modulators exert antidepressant activity (Wolkowitz et al., 1997, 1999; Urani et al., 2001). However, the mechanism of action of DHEA/S suggests an indirect way of normalizing HPA axis activity (via MAP2C protein activity, serotonin turn-over, anti-glucocorticoid effects, MAO inhibitory effect, promotion of neurogenesis, etc.) (Maninger et al., 2009; Pérez-Neri et al., 2009; Felice et al., 2012).

Taken altogether, these results showed that $3 \alpha 5 \beta-\mathrm{PG}$ activity at NMDARs lacks negative side-effects accompanying treatment with non-competitive NMDA antagonists that impair normal neurotransmission. Since PG combines both effects $-\mathrm{GABA}_{A}$ receptor potentiation and the NMDAR inhibition - it has a potential as an antidepressant in the treatment of depressive symptoms.

In conclusion, we demonstrated in animal models antidepressant-like and anxiolytic-like activities of $3 \alpha 5 \beta-\mathrm{PG}-$ an analog of naturally occurring $3 \alpha 5 \beta$-pregnanolone sulfate. PG is an example of a promising neurosteroid showing possible potential for development of a novel antidepressant, procognitive, and neuroprotective agents. This branch of research gives rise to a possibility of obtaining drugs with antidepressant/anxiolytic properties and minimal side-effects, i.e., with a more favorable risk/ benefit ratio.

\section{ACKNOWLEDGMENTS}

This study was supported by GACR grants P304/12/G069, P303/12/1464 IGA MZCR NT 13403-4/2012; TACR-TE01020028, institutional support RVO: 67985823, ACIU LM2011017 and by the project "CEITEC - Central European Institute of Technology" (CZ.1.05/1.1.00/02.0068) from the European Regional Development Fund. We would like to thank Michaela Fialova and Zdenka Oplatkova for their technical assistance. Next, we are appreciative to Dr. Ladislav Vyklicky, Dr. Hana Chodounska, and Dr. Eva Kudova for scientific inspiration and for steroid synthesis. Finally, we want to express thanks to Ms. Thuy Hua for proofreading.

\section{REFERENCES}

Aldred, S., and Mecocci, P. (2010). Decreased dehydroepiandrosterone (DHEA) and dehydroepiandrosterone sulfate (DHEAS) concentrations in plasma of Alzheimer's disease (AD) patients. Arch. Gerontol. Geriatr. 51, e16-e18. doi:10. 1016/j.archger.2009.07.001

Benes, F. M., Lim, B., Matzilevich, D., Subburaju, S., and Walsh, J. P. (2008). Circuitrybased gene expression profiles in GABA cells of the trisynaptic pathway in schizophrenics versus bipolars. Proc. Natl. Acad. Sci. U.S.A. 105, 20935-20940. doi:10.1073/pnas.0810153105

Berman, R. M., Cappiello, A., Anand, A., Oren, D. A., Heninger, G. R., Charney, D. S., et al. (2000). Antidepressant effects of ketamine in depressed patients. Biol. Psychiatry 47, 351-354. doi:10.1016/S0006-3223(99)00230-9

Biggio, G., and Purdy, R. H. (2001). Neurosteroids and Brain Function. San Diego, CA: Academic Press.

Blanchard, R. J., McKittrick, C. R., and Blanchard, D. C. (2001). Animal models of social stress: effects on behavior and brain neurochemical systems. Physiol. Behav. 73, 261-271. doi:10.1016/S0031-9384(01)00449-8

Borovska, J., Vyklicky, V., Stastna, E., Kapras, V., Slavikova, B., Horak, M., et al. (2012). Access of inhibitory neurosteroids to the NMDA receptor. Br. J. Pharmacol. 166, 1069-1083. doi:10.1111/j.1476-5381.2011.01816.x

Brot, M. D., Akwa, Y., Purdy, R. H., Koob, G. F., and Britton, K. T. (1997). The anxiolytic-like effects of the neurosteroid allopregnanolone: interactions with GABA(A) receptors. Eur. J. Pharmacol. 325, 1-7. doi:10.1016/S0014-2999(97) 00096-4

Browne, C. A., and Lucki, I. (2013). Antidepressant effects of ketamine: mechanisms underlying fast-acting novel antidepressants. Front. Pharmacol. 4:161. doi:10.3389/fphar.2013.00161

Bubeníková-Valesová, V., Horácek, J., Vrajová, M., and Höschl, C. (2008). Models of schizophrenia in humans and animals based on inhibition of NMDA receptors. Neurosci. Biobehav. Rev. 32, 1014-1023. doi:10.1016/j.neubiorev.2008.03.012

Burgdorf, J., Zhang, X. L., Nicholson, K. L., Balster, R. L., Leander, J. D., Stanton, P. K., et al. (2013). GLYX-13, a NMDA receptor glycine-site functional partial agonist, induces antidepressant-like effects without ketamine-like side effects. Neuropsychopharmacology 38, 729-742. doi:10.1038/npp.2012.246

Chaouloff, F. (2013). Social stress models in depression research: what do they tell us? Cell Tissue Res. 354, 179-190. doi:10.1007/s00441-013-1606-x

Chen, H. S., and Lipton, S. A. (2006). The chemical biology of clinically tolerated NMDA receptors antagonist. J. Neurochem. 97, 1611-1626. doi:10.1111/j.14714159.2006.03991.x

Croarkin, P. E., Levinson, A. J., and Daskalakis, Z. J. (2011). Evidence for GABAergic inhibitory deficits in major depressive disorder. Neurosci. Biobehav. Rev. 35, 818-825. doi:10.1016/j.neubiorev.2010.10.002

Danysz, W., Parsons, C. G., Karcz-Kubicha, M., Schwaier, A., Popik, P., Wedzony, K., et al. (1998). GlycineB antagonists as potential therapeutic agents. Previous hopes and present reality. Amino Acids 14, 235-239. doi:10.1007/BF01345268

Diazgranados, N., Ibrahim, L. A., Brutsche, N. E., Ameli, R., Henter, I. D., Luckenbaugh, D. A., et al. (2010). Rapid resolution of suicidal ideation after a single 
infusion of an N-methyl-D-aspartate antagonist in patients with treatmentresistant major depressive disorder. J. Clin. Psychiatry 71, 1605-1611. doi:10. 4088/JCP.09m05327blu

Entsuah, A. R., Huang, H., and Thase, M. E. (2001). Response and remission rates in different subpopulations with major depressive disorder administered venlafaxine, selective serotonin reuptake inhibitors, or placebo. J. Clin. Psychiatry 62, 869-877. doi:10.4088/JCP.v62n1106

Eser, D., Romeo, E., Baghai, T. C., di Michele, F., Schüle, C., Pasini, A., et al. (2006). Neuroactive steroids as modulators of depression and anxiety. Neuroscience 138, 1041-1048. doi:10.1016/j.neuroscience.2005.07.007

Felice, D., O'Leary, O. F., Pizzo, R. C., and Cryan, J. F. (2012). Blockade of the $\mathrm{GABA}(\mathrm{B})$ receptor increases neurogenesis in the ventral but not dorsal adult hippocampus: relevance to antidepressant action. Neuropharmacology 63, 1380-1388. doi:10.1016/j.neuropharm.2012.06.066

Gibbs, T. T., Russek, S. J., and Farb, D. H. (2006). Sulfated steroids as endogenous neuromodulators. Pharmacol. Biochem. Behav. 84, 555-567. doi:10.1016/j.pbb. 2006.07.031

Hayley, S., and Litteljohn, D. (2014). Neuroplasticity and the next wave of antidepressant strategies. Front. Cell Neurosci. 7:218. doi:10.3389/fncel.2013.00218

Hoffman, A. R., Ceda, G., and Reisine, T. D. (1985). Corticotropin-releasing factor desensitization of adrenocorticotropic hormone release is augmented by arginine vasopressin. J. Neurosci. 5, 234-242.

Huhman, K. L. (2006). Social conflict models: can they inform us about human psychopathology? Horm. Behav. 50, 640-646. doi:10.1016/j.yhbeh.2006.06.022

Irwin, R. P., Lin, S. Z., Rogawski, M. A., Purdy, R. H., and Paul, S. M. (1994). Steroid potentiation and inhibition of $\mathrm{N}$-methyl-D-aspartate receptor-mediated intracellular Ca++ responses: structure-activity studies. J. Pharmacol. Exp. Ther. 271, 677-682.

Jasnow, A. M., Cooper, M. A., and Huhman, K. L. (2004). N-methyl-D-aspartate receptors in the amygdala are necessary for the acquisition and expression of conditioned defeat. Neuroscience 123, 625-634. doi:10.1016/j.neuroscience.2003. 10.015

Jasnow, A. M., and Huhman, K. L. (2001). Activation of GABA(A) receptors in the amygdala blocks the acquisition and expression of conditioned defeat in Syrian hamsters. Brain Res. 920, 142-150. doi:10.1016/S0006-8993(01)03054-2

Karcz-Kubicha, M., Wedzony, K., Zajaczkowski, W., and Danysz, W. (1999). NMDA receptor antagonists acting at the glycineB site in rat models for antipsychoticlike activity. J. Neural. Transm. 106, 1189-1204. doi:10.1007/s007020050233

Kemp, J. A., and McKernan, R. M. (2002). NMDA receptor pathways as drug targets. Nat. Neurosci. 5(Suppl.), 1039-1042. doi:10.1038/nn936

Kim, S. B., Hill, M., Kwak, Y. T., Hampl, R., Jo, D. H., and Morfin, R. (2003). Neurosteroids: cerebrospinal fluid levels for Alzheimer's disease and vascular dementia diagnostics. J. Clin. Endocrinol. Metab. 88, 5199-5206. doi:10.1210/jc.2003030646

Korinek, M., Kapras, V., Vyklicky, V., Adamusova, E., Borovska, J., Vales, K., et al. (2011). Neurosteroid modulation of N-methyl-D-aspartate receptors: molecular mechanism and behavioral effects. Steroids 76, 1409-1418. doi:10.1016/j. steroids.2011.09.002

Krystal, J. H., Karper, L. P., Seibyl, J. P., Freeman, G. K., Delaney, R., Bremner, J. D., et al. (1994). Subanesthetic effects of the noncompetitive NMDA antagonist, ketamine, in humans. Psychotomimetic, perceptual, cognitive, and neuroendocrine responses. Arch. Gen. Psychiatry 51, 199-214. doi:10.1001/archpsyc. 1994.03950030035004

Kussius, C. L., Kaur, N., and Popescu, G. K. (2009). Pregnanolone sulfate promotes desensitization of activated NMDA receptors. J. Neurosci. 29, 6819-6827. doi:10.1523/JNEUROSCI.0281-09.2009

Lam, R. W. (2012). Onset, time course and trajectories of improvement with antidepressants. Eur. Neuropsychopharmacol. 22(Suppl. 3), S492-S498. doi:10.1016/ j.euroneuro.2012.07.005

Lapidus, K. A., Soleimani, L., and Murrough, J. W. (2013). Novel glutamatergic drugs for the treatment of mood disorders. Neuropsychiatr. Dis. Treat. 9, 1101-1112. doi:10.2147/NDT.S36689

Layer, R. T., Popik, P., Olds, T., and Skolnick, P. (1995). Antidepressant-like actions of the polyamine site NMDA antagonist, eliprodil (SL-82.0715). Pharmacol. Biochem. Behav. 52, 621-627. doi:10.1016/0091-3057(95)00155-P

Li, N., Liu, R. J., Dwyer, J. M., Banasr, M., Lee, B., Son, H., et al. (2011). Glutamate N-methyl-D-aspartate receptor antagonists rapidly reverse behavioral and synaptic deficits caused by chronic stress exposure. Biol. Psychiatry 69, 754-761. doi:10.1016/j.biopsych.2010.12.015
Lipton, A. S. (2006). NMDA receptors, glial cells, and clinical medicine. Neuron 50, 9-11. doi:10.1016/j.neuron.2006.03.026

Lipton, A. S. (2007). Pathologically activated therapeutics for neuroprotection. Nat. Rev. Neurosci. 8, 803-808. doi:10.1038/nrn2260

Luchetti, S., Bossers, K., Frajese, G. V., and Swaab, D. F. (2010). Neurosteroid biosynthetic pathway changes in substantia nigra and caudate nucleus in Parkinson's disease. Brain Pathol. 20, 945-951. doi:10.1111/j.1750-3639.2010.00396.x

Lucki, I., Dalvi, A., and Mayorga, A. J. (2001). Sensitivity to the effects of pharmacologically selective antidepressants in different strains of mice. Psychopharmacology (Berl.) 155, 315-322. doi:10.1007/s002130100694

MacKenzie, E. M., Odontiadis, J., Le Mellédo, J. M., Prior, T. I., and Baker, G. B. (2007). The relevance of neuroactive steroids in schizophrenia, depression, and anxiety disorders. Cell. Mol. Neurobiol. 27, 541-574. doi:10.1007/s10571-0069086-0

Maninger, N., Wolkowitz, O. M., Reus, V. I., Epel, E. S., and Mellon, S. H. (2009). Neurobiological and neuropsychiatric effects of dehydroepiandrosterone (DHEA) and DHEA sulfate (DHEAS). Front. Neuroendocrinol. 30:65-91. doi:10.1016/j.yfrne.2008.11.002

Mason, S. S., Baker, K. B., Davis, K. W., Pogorelov, V. M., Malbari, M. M., Ritter, R., et al. (2009). Differential sensitivity to SSRI and tricyclic antidepressants in juvenile and adult mice of three strains. Eur. J. Pharmacol. 602, 306-315. doi:10.1016/j.ejphar.2008.11.010

Meerlo, P., Overkamp, G. J., Benning, M. A., Koolhaas, J. M., and Van den Hoofdakker, R. H. (1996). Long-term changes in open field behaviour following a single social defeat in rats can be reversed by sleep deprivation. Physiol. Behav. 60, 115-119. doi:10.1016/0031-9384(95)02271-6

Morrow, A. L. (2007). Recent developments in the significance and therapeutic relevance of neuroactive steroids - introduction to the special issue. Pharmacol. Ther. 116, 1-6. doi:10.1016/j.pharmthera.2007.04.003

Murrough, J. W., Perez, A. M., Pillemer, S., Stern, J., Parides, M. K., Aan Het Rot, M., et al. (2013). Rapid and longer-term antidepressant effects of repeated ketamine infusions in treatment-resistant major depression. Biol. Psychiatry 74, 250-256. doi:10.1016/j.biopsych.2012.06.022

Nafziger, A. N., Bowlin, S. J., Jenkins, P. L., and Pearson, T. A. (1998). Longitudinal changes in dehydroepiandrosterone concentrations in men and women. J. Lab. Clin. Med. 131, 316-323. doi:10.1016/S0022-2143(98)90181-0

Olivares, E. L., Silva-Almeida, C., Pestana, F. M., Sonoda-Côrtes, R., Araujo, I. G., Rodrigues, N. C., et al. (2012). Social stress-induced hypothyroidism is attenuated by antidepressant treatment in rats. Neuropharmacology 62, 446-456. doi:10.1016/j.neuropharm.2011.08.035

Parsons, C. G. (2001). NMDA receptors as targets for drug action in neuropathic pain. Eur. J. Pharmacol. 429, 71-78. doi:10.1016/S0014-2999(01)01307-3

Pérez-Neri, I., Montes, S., and Ríos, C. (2009). Inhibitory effect of dehydroepiandrosterone on brain monoamine oxidase activity: in vivo and in vitro studies. Life Sci. 85, 652-656. doi:10.1016/j.lfs.2009.09.008

Petit-Demouliere, B., Chenu, F., and Bourin, M. (2005). Forced swimming test in mice: a review of antidepressant activity. Psychopharmacology (Berl.) 177, 245-255. doi:10.1007/s00213-004-2048-7

Petrovic, M., Sedlacek, M., Horak, M., Chodounska, H., and Vyklický, L. Jr. (2005). 20-oxo-5beta-pregnan-3alpha-yl sulfate is a use-dependent NMDA receptor inhibitor. J. Neurosci. 25, 8439-8450. doi:10.1523/JNEUROSCI.1407-05.2005

Pilc, A., Wieronska, J. M., and Skolnick, P. (2013). Glutamate-based antidepressants: preclinical psychopharmacology. Biol. Psychiatry 73, 1125-1132. doi:10.1016/j. biopsych.2013.01.021

Pinna, G., Agis-Balboa, R. C., Pibiri, F., Nelson, M., Guidotti, A., and Costa, E. (2008). Neurosteroid biosynthesis regulates sexually dimorphic fear and aggressive behavior in mice. Neurochem. Res. 33, 1990-2007. doi:10.1007/s11064-0089718-5

Pinna, G., Costa, E., and Guidotti, A. (2006). Fluoxetine and norfluoxetine stereospecifically and selectively increase brain neurosteroid content at doses that are inactive on 5-HT reuptake. Psychopharmacology (Berl.) 186, 362-372. doi:10.1007/s00213-005-0213-2

Pintér, O., Domokos, Á, Mergl, Z., Mikics, É, and Zelena, D. (2011). Do stress hormones connect environmental effects with behavior in the forced swim test? Endocr. J. 58, 395-407. doi:10.1507/endocrj.K10E-375

Pistovcakova, J., Makatsori, A., Sulcova, A., and Jezova, D. (2005). Felbamate reduces hormone release and locomotor hypoactivity induced by repeated stress of social defeat in mice. Eur. Neuropsychopharmacol. 15, 153-158. doi:10.1016/j. euroneuro.2004.08.007 
Popik, P., Mamczarz, J., Fraczek, M., Widła, M., Hesselink, M., and Danysz, W. (1998). Inhibition of reinforcing effects of morphine and naloxone-precipitated opioid withdrawal by novel glycine site and uncompetitive NMDA receptor antagonists. Neuropharmacology 37, 1033-1042. doi:10.1016/S0028-3908(98)00105-1

Porsolt, R. D., Anton, G., Blavet, N., and Jalfre, M. (1978). Behavioural despair in rats: a new model sensitive to antidepressant treatments. Eur. J. Pharmacol. 47, 379-391. doi:10.1016/0014-2999(78)90118-8

Pringle, A. K., Schmidt, W., Deans, J. K., Wulfert, E., Reymann, K. G., and Sundstrom, L. E. (2003). 7-Hydroxylated epiandrosterone (7-OH-EPIA) reduces ischaemiainduced neuronal damage both in vivo and in vitro. Eur. J. Neurosci. 18, 117-124. doi:10.1046/j.1460-9568.2003.02734.x

Rambousek, L., Bubenikova-Valesova, V., Kacer, P., Syslova, K., Kenney, J., Holubova, K., et al. (2011). Cellular and behavioural effects of a new steroidal inhibitor of the N-methyl-D-aspartate receptor $3 \alpha 5 \beta$-pregnanolone glutamate. Neuropharmacology 61, 61-68. doi:10.1016/j.neuropharm.2011.02.018

Razzoli, M., Carboni, L., and Arban, R. (2009). Alterations of behavioral and endocrinological reactivity induced by 3 brief social defeats in rats: relevance to human psychopathology. Psychoneuroendocrinology 34, 1405-1416. doi:10.1016/j.psyneuen.2009.04.018

Rodgers, R. J., and Johnson, N. J. (1998). Behaviorally selective effects of neuroactive steroids on plus-maze anxiety in mice. Pharmacol. Biochem. Behav. 59, 221-232. doi:10.1016/S0091-3057(97)00339-0

Rodríguez-Landa, J. F., Contreras, C. M., and García-Ríos, R. I. (2009). Allopregnanolone microinjected into the lateral septum or dorsal hippocampus reduces immobility in the forced swim test: participation of the GABAA receptor. Behav. Pharmacol. 20, 614-622. doi:10.1097/FBP.0b013e328331b9f2

Rogóz, Z., Skuza, G., Maj, J., and Danysz, W. (2002). Synergistic effect of uncompetitive NMDA receptor antagonists and antidepressant drugs in the forced swimming test in rats. Neuropharmacology 42, 1024-1030. doi:10.1016/S00283908(02)00055-2

Romeo, E., Ströhle, A., Spalletta, G., di Michele, F., Hermann, B., Holsboer, F., et al. (1998). Effects of antidepressant treatment on neuroactive steroids in major depression. Am. J. Psychiatry 155, 910-913.

Rygula, R., Abumaria, N., Flügge, G., Fuchs, E., Rüther, E., and Havemann-Reinecke, U. (2005). Anhedonia and motivational deficits in rats: impact of chronic social stress. Behav. Brain Res. 162, 127-134. doi:10.1016/j.bbr.2005.03.009

Schüle, C., Eser, D., Baghai, T. C., Nothdurfter, C., Kessler, J. S., and Rupprecht, R. (2011). Neuroactive steroids in affective disorders: target for novel antidepressant or anxiolytic drugs? Neuroscience 191, 55-77. doi:10.1016/j.neuroscience. 2011.03.025

Schüle, C., Nothdurfter, C., and Rupprecht, R. (2014). The role of allopregnanolone in depression and anxiety. Prog. Neurobiol. 113, 79-87. doi:10.1016/j.pneurobio. 2013.09.003

Sequeira-Cordero, A., Mora-Gallegos, A., Cuenca-Berger, P., and Fornaguera-Trías, J. (2013). Individual differences in the immobility behavior in juvenile and adult rats are associated with monoaminergic neurotransmission and with the expression of corticotropin-releasing factor receptor 1 in the nucleus accumbens. Behav. Brain Res. 252, 77-87. doi:10.1016/j.bbr.2013.05.046

Serra, M., Pisu, M. G., Littera, M., Papi, G., Sanna, E., Tuveri, F., et al. (2000). Social isolation-induced decreases in both the abundance of neuroactive steroids and GABA(A) receptor function in rat brain. J. Neurochem. 75, 732-740. doi:10.1046/j.1471-4159.2000.0750732.x

Sorwell, K. G., and Urbanski, H. F. (2010). Dehydroepiandrosterone and age-related cognitive decline. Age (Dordr). 32, 61-67. doi:10.1007/s11357-009-9113-4

Sulcova, A., and Krsiak, M. (1987). Differences among nine 1,4-benzodiazepines: an ethopharmacological evaluation in mice. Psychopharmacology (Berl.) 97, 157-159. doi:10.1007/BF00442240

Thase, M. E., Haight, B. R., Richard, N., Rockett, C. B., Mitton, M., and Modell, J. G. (2005). Remission rates following antidepressant therapy with bupropion or selective serotonin reuptake inhibitors: a meta-analysis of original data from 7 randomized controlled trials. J. Clin. Psychiatry 66, 974-981. doi:10.4088/JCP.v66n0803

Trullas, R., and Skolnick, P. (1990). Functional antagonists at the NMDA receptor complex exhibit antidepressant actions. Eur. J. Pharmacol. 185, 1-10. doi:10.1016/0014-2999(90)90204-J

Urani, A., Roman, F. J., Phan, V. L., Su, T. P., and Maurice, T. (2001). The antidepressant-like effect induced by sigma(1)-receptor agonists and neuroactive steroids in mice submitted to the forced swimming test. J. Pharmacol. Exp. Ther. 298, 1269-1279.
Uzunov, D. P., Cooper, T. B., Costa, E., and Guidotti, A. (1996). Fluoxetine-elicited changes in brain neurosteroid content measured by negative ion mass fragmentography. Proc. Natl. Acad. Sci. U.S.A. 93, 12599-12604. doi:10.1073/pnas.93.22. 12599

Uzunova, V., Sheline, Y., Davis, J. M., Rasmusson, A., Uzunov, D. P., Costa, E., et al. (1998). Increase in the cerebrospinal fluid content of neurosteroids in patients with unipolar major depression who are receiving fluoxetine or fluvoxamine. Proc. Natl. Acad. Sci. U.S.A. 95, 3239-3244. doi:10.1073/pnas.95.6.3239

Vales, K., Rambousek, L., Holubova, K., Svoboda, J., Bubenikova-Valesova, V., Chodounska, H., et al. (2012). 3 $\alpha 5 \beta$-Pregnanolone glutamate, a use-dependent NMDA antagonist, reversed spatial learning deficit in an animal model of schizophrenia. Behav. Brain Res. 235, 82-88. doi:10.1016/j.bbr.2012.07.020

Vallée, M., Mayo, W., Darnaudéry, M., Corpéchot, C., Young, J., Koehl, M., et al. (1997). Neurosteroids: deficient cognitive performance in aged rats depends on low pregnenolone sulfate levels in the hippocampus. Proc. Natl. Acad. Sci. U.S.A. 94, 14865-14870. doi:10.1073/pnas.94.26.14865

van Bokhoven, P., Oomen, C. A., Hoogendijk, W. J., Smit, A. B., Lucassen, P. J., and Spijker, S. (2011). Reduction in hippocampal neurogenesis after social defeat is long-lasting and responsive to late antidepressant treatment. Eur. J. Neurosci. 33, 1833-1840. doi:10.1111/j.1460-9568.2011.07668.x

Veiga, S., Garcia-Segura, L. M., and Azcoitia, I. (2003). Neuroprotection by the steroids pregnenolone and dehydroepiandrosterone is mediated by the enzyme aromatase. J. Neurobiol. 56, 398-406. doi:10.1002/neu.10249

Venzala, E., García-García, A. L., Elizalde, N., Delagrange, P., and Tordera, R. M. (2012). Chronic social defeat stress model: behavioral features, antidepressant action, and interaction with biological risk factors. Psychopharmacology (Berl.) 224, 313-325. doi:10.1007/s00213-012-2754-5

Venzala, E., García-García, A. L., Elizalde, N., and Tordera, R. M. (2013). Social vs. environmental stress models of depression from a behavioural and neurochemical approach. Eur. Neuropsychopharmacol.23, 697-708. doi:10.1016/j.euroneuro. 2012.05.010

Weaver, C. E., Land, M. B., Purdy, R. H., Richards, K. G., Gibbs, T. T., and Farb, D. H. (2000). Geometry and charge determine pharmacological effects of steroids on N-methyl-D-aspartate receptor-induced $\mathrm{Ca}(2+)$ accumulation and cell death. J. Pharmacol. Exp. Ther. 293, 747-754.

Wolkowitz, O. M., Reus, V. I., Keebler, A., Nelson, N., Friedland, M., Brizendine, L., et al. (1999). Double-blind treatment of major depression with dehydroepiandrosterone. Am. J. Psychiatry 156, 646-649.

Wolkowitz, O. M., Reus, V. I., Roberts, E., Manfredi, F., Chan, T., Raum, W. J., et al. (1997). Dehydroepiandrosterone (DHEA) treatment of depression. Biol. Psychiatry 41, 311-318. doi:10.1016/S0006-3223(96)00043-1

Zarate, C. A. Jr., Brutsche, N. E., Ibrahim, L., Franco-Chaves, J., Diazgranados, N., Cravchik, A., et al. (2012). Replication of ketamine's antidepressant efficacy in bipolar depression: a randomized controlled add-on trial. Biol. Psychiatry 71, 939-946. doi:10.1016/j.biopsych.2011.12.010

Zarate, C. A. Jr., Singh, J. B., Carlson, P. J., Brutsche, N. E., Ameli, R., Luckenbaugh, D. A., et al. (2006). A randomized trial of an N-methyl-D-aspartate antagonist in treatment-resistant major depression. Arch. Gen. Psychiatry 63, 856-864. doi:10.1001/archpsyc.63.8.856

Zorumski, C. F., Paul, S. M., Izumi, Y., Covey, D. F., and Mennerick, S. (2013). Neurosteroids, stress and depression: potential therapeutic opportunities. Neurosci. Biobehav. Rev. 37, 109-122. doi:10.1016/j.neubiorev.2012.10.005

Conflict of Interest Statement: The authors declare that the research was conducted in the absence of any commercial or financial relationships that could be construed as a potential conflict of interest.

Received: 19 December 2013; accepted: 29 March 2014; published online: 16 April 2014. Citation: Holubova K, Nekovarova T, Pistovcakova J, Sulcova A, Stuchlík A and Vales $K$ (2014) Pregnanolone glutamate, a novel use-dependent NMDA receptor inhibitor, exerts antidepressant-like properties in animal models. Front. Behav. Neurosci. 8:130. doi: 10.3389/fnbeh.2014.00130

This article was submitted to the journal Frontiers in Behavioral Neuroscience.

Copyright (๑) 2014 Holubova, Nekovarova, Pistovcakova, Sulcova, Stuchlik and Vales. This is an open-access article distributed under the terms of the Creative Commons Attribution License (CC BY). The use, distribution or reproduction in other forums is permitted, provided the original author(s) or licensor are credited and that the original publication in this journal is cited, in accordance with accepted academic practice. No use, distribution or reproduction is permitted which does not comply with these terms. 